\title{
Ocular Complications of Diabetes Mellitus Except for Diabetic Retinopathy
}

\author{
Chantal Makita $^{1,2}$, Charles Géraud Fredy Nganga Ngabou ${ }^{1,2, *}$, Eyissa Nzi Gombé1, \\ Reinette Messe Ambia Koulimaya ${ }^{2}$
}

${ }^{1}$ Faculty of Health Sciences, University Marien Ngouabi, Brazzaville, Congo

${ }^{2}$ Department of Ophthalmology, University Hospital, Brazzaville, Congo

Email address:

Chantalmakita@gmail.com (C. Makita), fredygeraud@gmail.com (C. G. F. N. Ngabou), geyissa@gmail.com (E. N. Gombé), mchkr_n@yahoo.fr (R. M. A. Koulimaya)

${ }^{*}$ Corresponding author

\section{To cite this article:}

Chantal Makita, Charles Géraud Fredy Nganga Ngabou, Eyissa Nzi Gombé, Reinette Messe Ambia Koulimaya. Ocular Complications of Diabetes Mellitus Except for Diabetic Retinopathy. International Journal of Ophthalmology \& Visual Science. Vol. 4, No. 4, 2019 , pp. 77-80. doi: $10.11648 /$ j.ijovs.20190404.14

Received: September 27, 2019; Accepted: October 29, 2019; Published: November 5, 2019

\begin{abstract}
The Ocular complications of diabetes mellitus except for diabetic retinopathy have been poorly studied compared retinal complications, which are the main cause of blindness. We report the results of a prospective study reviewing the different ocular conditions encountered during diabetes. Four hundred (400) eyes of two hundred (200) patients with type 1 and type 2 diabetes were examined during a period of 8 months. All included patients underwent a complete ophthalmological examination. Fifty-seven diabetic patients were diagnosed of an ocular disease at a frequency of $28.5 \%$. There were 42 male and 17 female patients with an average age of 57, 5 years old. The average duration of diabetes was 11.8 years. Non-insulindependent diabetes mellitus was present in $59.6 \%$ of cases. Cataracts were the most common ocular diseases diagnosed in $45.6 \%$ of cases followed by primary or chronic open-angle glaucoma in $22.9 \%$ and hyperopia in $12.3 \%$ of cases. Corneal sensitivity was decreased in $52 \%$ of cases and bilateral optic neuropathy was found in $3.4 \%$ of cases (two hundred eyes). The ocular complications of diabetes mellitus except for diabetic retinopathy, are dominated by cataracts and glaucoma. But there are also neuropathies that may cause blindness. These conditions should therefore also be systematically screened for evaluations and reviews of potential degenerative complications in patients with diabetes mellitus.
\end{abstract}

Keywords: Type 1 and Type 2 Diabetes Mellitus, Cataract, Glaucoma, Refractive Error

\section{Introduction}

The complications occurring in diabetes mellitus affect the vast majority of the components of the eye $[1,2]$. They are described in two groups: ocular complications directly related to diabetes mellitus, especially diabetic retinopathy which is the major clinical form and the leading cause of blindness and low vision in people under 60 in industrialized countries [3,4] and will not be part of our study - cataract, refraction changes, corneal damage; ocular complications for which diabetes mellitus is considered a known or possible risk factor. These include glaucoma, oculomotor nerve palsy (ONP), acute anterior ischemic neuropathy. Unlike diabetic retinopathy, other ocular disorders related to diabetes mellitus have been poorly understood. Hence, we studied ocular complications of diabetes mellitus except for diabetic retinopathy.

\section{Patient and Methods}

This is a prospective study conducted in outpatients with type 1 or type 2 diabetes mellitus followed in the Department of Metabolic and Endocrine Diseases, then sent to the Department of Ophthalmology at the University Hospital of Brazzaville for ophthalmic examination. During a period of 8 months from January to August 2019, inclusion of patients was carried out consecutively by the same examiner. All patients were examined under the same conditions and with 
the same devices.

During the study period 200 patients were examined, ie 400 eyes, of which 144 were male and 56 were female. They had an average age of 55.8 years, with extremes of 15 to 72 years. Exclusion criteria were corneal pathologies, chronic or acute eye inflammation or infections.

Ophthalmologic examination included: measurement of near and far visual acuity with correction, study of ocular motility, examination of appendages, central corneal sensitivity was tested with cotton-wisp, ultrasound biomicroscopy for assessment of the anterior segment, measurement of the intraocular pressure by the air-puff tonometer and fundus examination with indirect ophthalmoscopy with Volk lens.

The various diabetes-related parameters analyzed were: evolution of diabetes, type, balance of diabetes, and association with high blood pressure.

The patients were distributed according to the type of diabetes mellitus: Type 1 (insulin-dependent) diabetes mellitus (IDDM); and Type 2 (non-insulin-dependent) diabetes mellitus (IDDM) divided into two groups including patients with adequate glycemic control by diet or oral hypoglycemic agents and patient with insulin-requiring diabetes mellitus (IRDM). The balance of diabetes was quantified in 3 stages (good, medium or poor) based on biological data (glycemic index, glycosylated hemoglobin).

The variables in the study were: dependent variables (diabetic patients, ocular lesions); independent variables (age, sex, type of diabetes, evolution of diabetes, balance of diabetes). The results were processed by the standard error for the estimation of frequencies, the Excel software for the analysis of data series.

\section{Results}

Fifty-seven (57) diabetic patients had an ocular lesion with a hospital frequency of $(28.5 \%)$. There were 42 male patients $(73.7 \%)$ and 15 female $(26.3 \%)$ with a sex ratio of 2.8 . The age of the patients ranged from 15 years to 72 years with an average of 57, 5 years. The age group from 51 and over was $45.6 \%$, that of $41-50$ was $35 \%, 31-40$ was $15.8 \%$ and 2 patients were under 30 years of age.

Table 1. Disease distribution by sex.

\begin{tabular}{llll}
\hline Diseases & Males (\%) & Females (\%) & Total (\%) \\
\hline Cataract & 31,6 & 14.0 & 45.6 \\
Glaucoma & 19,3 & 3.5 & 22,8 \\
Hypermetropia & 8,7 & 3.5 & 12.3 \\
Myopia & 5.3 & 1,7 & 7.0 \\
Bilateral optic & 1.7 & 1.7 & 3.5 \\
neuropathy & & & \\
Bilateral paralysis of & 3.5 & - & 3.5 \\
cranial nerve III & 3.5 & - & 3.5 \\
Recurrent Chalazion & - & 1.7 & 1.7 \\
Rubeosis iridis & 73.7 & 26.3 & 100 \\
Total & & & \\
\hline
\end{tabular}

Cataract accounted for $45.6 \%$ of complications, $31.6 \%$ of which were men.
Table 2. Distribution of diseases by age.

\begin{tabular}{|c|c|c|c|c|c|}
\hline \multirow[b]{2}{*}{ Diseases } & \multicolumn{4}{|c|}{ Age group (years)\% } & \multirow{2}{*}{ Total\% } \\
\hline & $\leq \mathbf{3 0}$ & $31-40$ & 41-50 & 51 et plus & \\
\hline Cataract & 1,7 & 5.3 & 14,0 & 24,6 & 45.6 \\
\hline Glaucoma & - & 3.5 & 7.0 & 12.3 & 22.8 \\
\hline Hypermetropia & - & 3.5 & 5.2 & 3.5 & 12.2 \\
\hline Myopia & - & 1.7 & 3.5 & 1.7 & 7.0 \\
\hline $\begin{array}{l}\text { Bilateral optic } \\
\text { neuropathy }\end{array}$ & - & - & 1.7 & 1.7 & 3.4 \\
\hline $\begin{array}{l}\text { Bilateral paralysis of } \\
\text { cranial nerve III }\end{array}$ & - & - & 3.5 & - & 3.5 \\
\hline Recurrent Chalazion & 1.7 & 1.7 & - & - & 3.4 \\
\hline Rubeosis iridis & - & - & - & 1.7 & 1.7 \\
\hline Total & 3.5 & 15.8 & 35.0 & 45.7 & 100 \\
\hline
\end{tabular}

$35 \%$ of patients with complications were between 41 and 50 years old.

The average duration between the discovery of diabetes and the clinical examination was 11.8 years with extremes of 0.1 to 30 years and a significant prevalence between 6-11 years in half of the cases. Diabetes was non-insulindependent (NIDDM) in $59.6 \%$ of cases, insulin-requiring (IRDM) in $29.9 \%$ and insulin-dependent (IDDM) in $10.5 \%$.

Table 3. Disease Distribution by Duration of Diabetes.

\begin{tabular}{|c|c|c|c|c|c|}
\hline \multirow[b]{2}{*}{ Diseases } & \multicolumn{4}{|c|}{ Diabetes evolution time (years)\% } & \multirow{2}{*}{ Total (\%) } \\
\hline & 5 & 6-11 & 12-17 & $>18$ & \\
\hline Cataract & 7.0 & 24.6 & 7.0 & 7.0 & 45.6 \\
\hline Glaucoma & 8.7 & 7.0 & 3.5 & 3.5 & 22.8 \\
\hline Hypermetropia & 5.2 & 3.5 & 1.7 & 1.7 & 12.2 \\
\hline Myopia & 3.5 & 1.7 & 1.7 & - & 7.0 \\
\hline $\begin{array}{l}\text { Bilateral optic } \\
\text { neuropathy }\end{array}$ & - & - & 1.7 & 1.7 & 3.4 \\
\hline $\begin{array}{l}\text { Bilateral paralysis of } \\
\text { cranial nerve III }\end{array}$ & & 1.7 & 1.7 & & 3.4 \\
\hline Recurrent Chalazion & 1.7 & 1.7 & - & - & 3.4 \\
\hline Rubeosis iridis & & 1.7 & - & - & 1.7 \\
\hline Total & 26.1 & 41.9 & 17.5 & 14.0 & 100 \\
\hline
\end{tabular}

$41.9 \%$ of patients with complications had a progression of diabetes between 6 and 11 years.

Table 4. Disease Distribution by Type of Diabetes.

\begin{tabular}{lllll}
\hline Diseases & $\begin{array}{l}\text { Type 1 } \\
(\%)\end{array}$ & $\begin{array}{l}\text { Type 2 } \\
\text { IRDM (\%) }\end{array}$ & $\begin{array}{l}\text { Type 2 } \\
\text { NIDDM (\%) }\end{array}$ & $\begin{array}{l}\text { Total } \\
(\%)\end{array}$ \\
\hline Cataract & 5.2 & 12.3 & 28.1 & 45.6 \\
Glaucoma & 3.5 & 8.7 & 10.5 & 22.8 \\
$\begin{array}{l}\text { Hypermetropia } \\
\text { Myopia }\end{array}$ & - & 5.2 & 7.0 & 12.2 \\
Bilateral optic & 1.7 & 3.5 & 1.7 & 7.0 \\
neuropathy & - & - & 3.5 & 3.5 \\
Bilateral paralysis of & - & 1.7 & 1.7 & 3.4 \\
cranial nerve III & & & 3.5 & 3.5 \\
Recurrent Chalazion & - & - & 1.8 & 1.8 \\
Rubeosis iridis & - & - & 58 & 100 \\
Total & 10.4 & 31.5 & & \\
\hline
\end{tabular}

The majority of patients had type II, non-insulin-dependent diabetes.

The balance of diabetes was good in $39 \%$ of cases, medium in $31 \%$ of cases, and poor $30 \%$ of cases. High blood pressure (HBP) was present in $36.5 \%$.

According to the complications found, cataracts were the most common diseases with $45.6 \%$ of cases and posterior subcapsular cataract predominated with $19.3 \%$ of cases, 
followed by total cataract $14 \%$.

Table 5. The distribution of cataract localization by age.

\begin{tabular}{|c|c|c|c|c|c|}
\hline \multirow[b]{2}{*}{ Cataract localization } & \multicolumn{4}{|c|}{ Age group (years) \% } & \multirow{2}{*}{ Total\% } \\
\hline & $\leq \mathbf{3 0}$ & $31-40$ & 41-50 & $>\mathbf{5 0}$ & \\
\hline $\begin{array}{l}\text { Posterior subcapsular } \\
\text { cataract }\end{array}$ & 7.7 & 7.7 & 19.2 & 7.7 & 42.3 \\
\hline Total cataract & - & - & 3.8 & 26.9 & 30.7 \\
\hline Corticonuclear cataract & - & - & 3.8 & 11.5 & 15.3 \\
\hline Cortical cataract & - & - & 7.7 & 3.8 & 11.5 \\
\hline Total & 7.7 & 7.7 & 34.6 & 50 & $(\mathrm{n}=26) 100$ \\
\hline
\end{tabular}

Posterior subcapsular cataract was the most common localization Primary or chronic open-angle glaucoma was present in $22.9 \%$ of cases, and hyperopia $12.3 \%$ of cases, decreased corneal sensitivity in $52 \%$ of cases $(n=200)$.

\section{Discussion}

Non-retinal ocular complications in diabetes are rarely reported in African literature. This study made it possible to analyze the influence of diabetes on certain structures of the eye other than the retina. We found a frequency of $28.5 \%$; this rate is lower compared to that of diabetic retinopathy which in some studies ranged from $50 \%$ to $60 \%[5,6]$. African studies have reported a male predominance in the occurrence of diabetic retinopathy $[5,7,8]$ that we found with a sex ratio of 2.8 .

According to the age of the patients our results are comparable to the data of the literature with a prevalence of the patients aged over $50[6,9,10]$, however the age and the existence of diabetes is not yet elucidated [10].

The duration of diabetes in our study is between 6 and 11 years in half of the cases. Studies such as those of BALO [5] show that the irregularity of the treatment with difficulties of normalization of the glycemia could explain the appearance of the complications earlier before 5 years of evolution of the diabetes.

During this study a prevalence of NIDDM was found in $61.5 \%$ of cases, which was also confirmed by various authors $[9,10]$. The factors causing ocular complications are numerous $[5,8]$. Our study confirmed some of them: The duration of evolution, the type of diabetes, its balance and the blood pressure level.

We studied the different diseases associated with diabetes and identified a significant frequency of cataracts in diabetics often between 40-50 years. The type of posterior capsular cataract is much more common $[10,11]$, the loss of lens transparency is due to the increase in the glucose level in the vitreous humor. However this type of cataract is not specific of an endocrine origin.

The relationship between open-angle glaucoma and diabetes remains controversial [13]. Some studies have found an increased frequency of ocular hypertension and glaucoma in diabetics [13, 14], others not [15]. A markedly high incidence of ocular hypertonia has been observed in type 2 diabetics [16]. These results do not seem to warrant more frequent screening for glaucoma in diabetic patients than in the general population.

Refractive disorders during diabetes are often present. We found $12.3 \%$ hyperopia and $7 \%$ myopia. Hyperopia is the rule, with refractive variations of up to 6.5 dioptres [17]. This phenomenon is sometimes added to accommodation disorders during the increase in blood glucose levels, which also affect diabetic patients. In these cases, normalization of ametropia is obtained as soon as the glucose level is controlled.

The measurement of the corneal sensitivity was made by a cotton-wisp placed perpendicular to the cornea so as to cause or not a sensory reaction. This sensitivity was reduced in $52 \%$ of cases of the entire diabetic population. Hypoaesthesia for some authors is often related to the existence of diabetes and age [18-19]. On the other hand, the etiopathogenesis of the decrease of the corneal sensitivity with the age or the existence of a diabetes is not yet completely described.

We found optic nerve damages in 2 cases in the form of pure optical neuropathy. In the literature it has been described by CHIARA [20] who divided it into 3 stages. In the first, physiological abnormalities alone can be noted without signs of loss of nerve fibers. In the second stage, nerve fiber losses or visual field changes can be detected without any visible sign of atrophy on ophthalmoscope examination. In the $3 \mathrm{rd}$ stage, the loss of nerve fibers becomes obvious and the optic nerve is pale. Both metabolic and vascular alterations explain these phenomena.

Oculomotor nerve damage was consistent to a bilateral III paralysis present in 2 cases. This rate is comparable to that of Ducrey [21].

The stye is one of infectious complications frequently found in diabetic patient with imbalanced levels of glucose.

Iris rubeosis was present in our study at a frequency of $3.5 \%$, which is similar to that of OHRT [22]. It is a dreadful complication. It can evolve into neovascular glaucoma resulting in irreversible IOP elevation.

This review of non retinal and non ocular complications of diabetes mellitus highlights the importance of regular followup of patients. The major improvement in the treatment of diabetes, the control of risk factors such as high blood pressure and the possibility of effective eye treatments, make it possible to prevent ocular complications of diabetes mellitus.

\section{Conclusion}

The complications occurring during diabetes are numerous, dominated by cataracts, glaucoma, refractive disorders, corneal hypoaesthesia. The parameters for the control of diabetes include disease evolution time which is the main factor with devastation effects on vision. These lesions allow to consider multifaceted and multidisciplinary actions to prevent and detect them as early as possible.

\section{References}

[1] Vieira-Potter VJ, Karamichos D, Lee DJ. Ocular Complications of Diabetes and Therapeutic Approaches. BioMed Research International 2016; 3801570. 
[2] Savin N, Kara N, Pekel G. Ocular complications of diabetes mellitus. World J Diabetes 2015; 6: 92-108.

[3] Sinclair SH. Diabetic retinopathy: The unmet needs for screening and review of potential solutions. Expert Rev Med Devices 2006; 3: 301-16.

[4] Franck RN. Diabetic retinopathy. N Engl J Med 2004; 350: 48-58.

[5] Balo KP, Mensah A, Koffi-Gue B. La rétinopathie diabétique: une étude angiographique chez le noir Africain. Méd Afr Noire, 1995; 42: 402-5.

[6] Massin-Korobelnik P, Guillausseau PJ. Hyperglycémie chronique et rétinopathie diabétique. Sang, Thrombose, vaisseaux 1992; 4: 3653-72.

[7] Koki G, Bella AL, Ongboua EA, Epée E, Sobngui E, Kouanane KA, Ebana MC, Mbanya JC. Rétinopathie diabétique du Noire africain étude angiographique. Cah Etude Rech Francophone/ santé 2010; 20, 3: 127-32.

[8] Sidibé EH. Rétinopathie diabétique à Dakar et revue de la littérature africaine: éléments épidémiologiques. Diabete Métab 2000; 26: 322.

[9] Rotami C, Daniel H, Zhou J, et al. Prévalence and determinants of diabetic. Rétinopathy and cataracts in west africain types 2 diabetes patients Ethn Dis 2003; 13 (2 suppl 2): $\mathrm{S} 110-7$.

[10] Touzeau O, Levet L, Borderie V, Bouchard P, Laroche L. Le segment antérieur de l'œil des diabétiques. J Fr Ophtalmol, 2007; 27, 8: 859-70.

[11] Offret G, Dhermy P. Métabolisme du cristallin et cataracte. J Fr Ophtalmol, 1988; 11: 369- 02.

[12] Ekkis JD, Evans JM, Ruta DA, Baines PS, Leese G, Mac Donald TM, et al. Glaucoma incidence unselected cohort of diabetic patients: is diabetes mellitus a risk factor for glaucoma? Br J Ophthalmol, 2000; 84: 1218-24.

[13] Nielsens NV. The prévalence of glaucoma and ocular hypertension in type 1 and 2 diabetes mellitus. Acta Ophthalmologica 1983; 61: 662-72.

[14] Klein BE, Klein R, Moss SE. Intraocular pressure in diabetic persons. Ophtalmology 1984; 91: 1356-60.

[15] Tielsch JM, Katz J, Quigley HA et al. Diabetes, intraocular pressure, and primary open-angle glaucoma in the Baltimore Eye Survery Ophtalmology 1995; 102: 48-53.

[16] Klein BE, Klein R, Jensen SC. Open-angle glaucoma and older-onset diabetes: the Beaver dam Eye study. Ophtalmology 1994; 101: 1173-7.

[17] Fledelius HC, Fuchs J, Reck A. Refraction in diabetes during metabolic dysregulation acute or chronic. Acta Ophthalmol 1990; 68: 275-80.

[18] Cochet P, Bonnet R. L'esthésie cornéenne. Clin Ophtalmol, 1960; 43-27.

[19] Ben Osman B, Jeddi A, Sebah L, Zghal I, Kaoueche M, Gaigi S, Ayed S. La cornée du diabétique. J Fr Ophtalmol 1995; 18: 120-3.

[20] Chiara E. Optic Neuropathy in diabetic patient. Focus on diabetic retinopathy $1996 ; 28-33$.

[21] Ducrey N. Les complications ophtalmologiques du diabète à l'exclusion de la rétinopathie diabétique. J Fr Ophtalmol 1999; 22: 400-7.

[22] OHRT V. The frequency of rubeosis iridis in diabetic patients. Acta Ophthalmol 1971; 49: 301-7. 